\title{
TODA A TERRA É DOS HOMES: PROFESORES GALLEGOS, EXILIO POLÍTICO Y ACCIÓN DOCENTE
}

\author{
The whole land belongs to men: \\ Galician Teachers, Political Exile and Teaching Action
}

\section{Gregorio Ferreiro Fente ${ }^{\&}$}

Fecha de recepción: 22/05/2018 • Fecha de aceptación: 04/07/2018

\section{A Antón Costa Rico, mestre.}

Resumen. Aunque resulte legítimo afirmar que la literatura existente sobre el exilio republicano gallego constituye, por sus abundantes y meritorios frutos, un relato bastante satisfactorio, no parece desacertado colegir que estamos ante un texto que permanece todavía inconcluso en muchos de sus capítulos, siendo indiscutiblemente uno de ellos la cuestión no suficientemente tratada hasta el momento en Galicia del exilio de sus docentes. Partiendo, pues, de esta tesis, en la que subyace además el escollo de que el exilio gallego ha sido acometido con frecuencia desde perspectivas que no siempre han sido las más apropiadas, se emprende el presente trabajo con el propósito de ofrecer un bosquejo a vista de pájaro y a menudo de trazos gruesos del fenómeno del exilio de los docentes, haciendo especial hincapié en los elementos que lo singularizaron en relación con otros exilios hispánicos, expresamente con aquellos que tuvieron su origen en territorios que permanecieron bajo la potestad del Gobierno legítimo tras el golpe de Estado de julio de 1936. A modo de recurso narrativo, se apelará a veces al relato biográfico de personalidades del magisterio cuyo periplo puede resultar, en un momento dado, un ejemplo paradigmático e instructivo sobre el hecho concreto objeto de nuestra atención. Igualmente, la mención del nombre de muchos de ellos supondrá, de modo indirecto, la confección del catálogo onomástico más completo de los realizados hasta el momento referido a los docentes originarios de Galicia que sufrieron el destierro.

Palabras clave: Historia de la educación; Exilio republicano; Docentes gallegos.

\footnotetext{
\& Consellería de Cultura, Educación e Ordenación Universitaria, Xunta de Galicia. Rúa de San Roque, 2.15704 Santiago de Compostela, España.gfente@edu.xunta.es.
}

Cómo citar este artículo: Ferreiro Fente, Gregorio. «Toda a terra é dos homes: Profesores gallegos, exilio político y acción docente». Historia y Memoria de la Educación 9 (2019): 139-171. 
Abstract. Although it is legitimate to state that the existing literature regarding the Galician republican exile provides us with a satisfactory account, due to its abundance and quality, we also believe that the subject remains unfinished in many of its chapters. One aspect that unquestionably demands more study has to do with the situation in Galicia of the exile of its teachers. Starting from this premise, we also believe that the issue of Galician exile has frequently been addressed from perspectives that were not entirely appropriate. In this article we would like to offer a rough sketch, a sort of "bird's eye view" of the phenomenon of teachers' exile, highlighting the elements that make it unique in relation to other Spanish exiles - especially those originating in territories that were under the government's legal authority after the coup d'état in July 1936-. As a narrative resource, we will sometimes resort to the biographical accounts of teaching figures whose journeys and ordeals ultimately serve as paradigmatic and educational examples of the specific fact which is the object of our attention. Furthermore, the fact of mentioning some of their names implies, indirectly, the first step in a more complete onomastic catalogue than we currently have of the many teachers from Galicia that were sent into exile.

Keywords: History of education; Republican exile; Galician teachers.

\section{GALICIA MÁRTIR}

Con este título, Alfonso Daniel Rodríguez Castelao publicaba, en febrero de 1937, un álbum de diez estampas cuya intención declarada era mostrarles «aos galegos que andan pol-o mundo» los estragos que estaba provocando la sanguinaria ocupación militar que sumía a Galicia en un horrible estado de terror desde el día 20 de julio anterior. La sexta de aquellas estampas reproduce, en la parte central de un paisaje yermo con horizonte difuso en el que se otean dos árboles secos, la imagen en primer plano de un hombre yacente, a cuyo lado un niño y un adolescente se lamentan en actitud de recogimiento orante y profunda aflicción. La estampa adquiere su significado pleno cuando se lee el pie: «A derradeira lección do mestre». ${ }^{1}$ No por azar, esa es la única lámina de todo el álbum en la que se hace alusión explícita a la profesión de la víc-

\footnotetext{
${ }^{1}$ Castelao, Galicia mártir (Madrid-Valencia: Ediciones Españolas, 1937). El pie de esta estampa está únicamente en gallego, pero, como ocurre también en todas las restantes, incluye traducción exenta en castellano ( «La última lección del maestro»), francés e inglés. Este hecho, sumado al de que la obra conoció, durante la guerra, otras cuatro ediciones además de la citada, certifica que, en realidad, los destinatarios de la publicación no eran solo los gallegos de la diáspora, como se declaraba en el prefacio.
} 
tima representada y en cuyo esquema compositivo el fondo pretende, más allá de reproducir un clima, emitir un mensaje nítido: el asesinato del maestro no solo era un ejemplo más de la violencia ciega desatada en Galicia, sino que constituía el símbolo del derrumbe absoluto de una sociedad aún a medio hacer que quedaba huérfana de la persona a la que, por la profesión que desempeñaba, se le había confiado la construcción de su porvenir.

Al político galleguista, polifacético artista y, desde 1916, profesor de Dibujo en el Instituto General y Técnico de Pontevedra, el levantamiento armado contra la República española de 1931 lo había sorprendido en Madrid, adonde se trasladara circunstancialmente, en su condición de diputado, para hacer entrega, el 15 de julio, del Estatuto de Autonomía de Galicia al Presidente de las Cortes después de su aprobación, el 28 de junio, mediante plebiscito popular. Tres días más tarde de aquel histórico momento - hito y símbolo sincrético del exitoso proceso de edificación cultural y política desarrollado por el galleguismo durante las décadas de 1920 y 1930 - , Castelao, aún en la capital de España, asistirá perplejo a las primeras noticias sobre la insurrección militar y a la inmediata declaración del estado de guerra por parte de los golpistas. Nunca más habría de regresar a tierras gallegas desde entonces y muy lejos de ellas, exiliado en Buenos Aires, encontraría la muerte el 7 de enero de 1950 tras más de una década de laboriosa entrega a la causa republicana y galleguista.

Se puede aventurar sin temor a caer en un desatino que el autor de Galicia mártir hubiera corrido una suerte trágica de no mediar la circunstancia de hallarse, en el momento de la sublevación militar, en Madrid y no en Galicia, donde los militares insurrectos, en apenas los seis días que van desde la tarde del 20 al 26 de julio, se acabarían adueñando del poder en prácticamente todo el territorio. No lograrían impedirlo ni las autoridades civiles republicanas, ni la renuencia o indecisión de no pocos mandos militares, ni, por supuesto, las mal pertrechadas juntas de defensa o los comités de huelga que, integrados por militantes de organizaciones políticas y sindicales adscritas a la coalición electoral del Frente Popular, se llegarían a constituir en todas las grandes ciudades, así como en numerosas pequeñas localidades, desde el mismo instante en que aparecen las primeras noticias de la asonada militar en el norte de África. La Galicia que el 16 de febrero había dado su apoyo 
mayoritario al Frente Popular en las elecciones a las Cortes quedaba, de esta forma y de la noche a la mañana, bajo la bota militar de los sublevados y sometida a los albures de un nuevo poder que, una vez que hubo logrado la rápida apropiación de las instituciones republicanas, se propuso de inmediato su consolidación social. Para ello, se serviría de una estructurada acción represiva que tuvo su momento álgido durante los seis meses posteriores al golpe de Estado.

Resulta cada vez más usual en el ámbito académico encuadrar la represión llevada a cabo en Galicia dentro de la categoría de práctica genocida, un concepto que se fundamenta, más que en una enfatización cuantificadora de las víctimas, en la consideración combinada de un grupo cerrado de elementos definidores, entre los que la intencionalidad y la justificación de la acción represora son determinantes. ${ }^{2}$ Las autoridades franquistas encontrarían una de sus principales justificaciones en una lógica de naturaleza quirúrgica, según la cual el cuerpo social gallego — como el español en su conjunto- estaba aquejado de un tumor que era necesario extirpar. Ciertamente el diagnóstico no era novedoso, pues se había venido configurando en España, como discurso ideológico, desde hacía décadas, pero sí la intencionalidad: la aniquilación física o mediante enajenación de un colectivo, conformado por individuos con una gemela identidad política, al que se reconocía como el mal a erradicar. La facultad de atribuir la pertenencia (o no) a ese imaginario grupo humano - al igual que la construcción de la presunta identidad política aglutinadora- la ejercería el nuevo poder y no sus supuestos integrantes, que, dada su heterogeneidad ideológica, carecían de cualquier sentido de pertenencia corporativa única. Esto explica que en el mismo saco terminaran incluyéndose tanto un obrero comunista, un gobernador civil militante de Izquierda Republicana o un abogado galleguista de derechas y católico, como un militar que no se hubiese sumado a la rebelión o el funcionario de ayuntamiento cuya mayor muestra de adscripción a la conjeturada hermandad ideológica había consistido en acometer su trabajo respetando la legislación en vigor durante el período republicano.

El intenso y exhaustivo proceso represivo desarrollado en Galicia seguiría esta lógica de parte y de aplicación universal, de manera que

\footnotetext{
${ }^{2}$ Antonio Míguez Macho, O que fixemos en Galicia. Ensaio sobre o concepto de práctica xenocida (Ourense: Difusora de Letras, Artes e Ideas, 2009).
} 
toda la sociedad gallega se vería constreñida a una suerte de estado general de cuarentena cuya finalidad última sería identificar y erradicar del cuerpo social a aquellos individuos considerados como dañosos. Los datos de los que se dispone apuntan hacia una interpretación en esta dirección y desmienten en buena medida ciertos tópicos aún extendidos como el de que dicha purga se infligió mayormente en determinadas profesiones y no tanto en otras. Confirma esta tesis el hecho de que el porcentaje de víctimas de ejecuciones y de asesinatos extrajudiciales que se llevaron a cabo durante el período 1936-1939 se distribuyó casi por igual, sin diferencias sustanciales, entre los distintos grupos sociolaborales: un $38,8 \%$ pertenecían a las clases medias y profesionales, un $35,5 \%$ eran obreros o artesanos y un $23,95 \%$, labradores o marineros. ${ }^{3}$

Si bien carecemos de estudios comparativos referidos específicamente al ámbito profesional de la enseñanza, se puede afirmar que la misma argumentación general es trasladable a este colectivo, y concluir, como ya intuyó hace años el profesor Antón Costa Rico, que los docentes no fueron objeto de una represión diferenciada en términos cuantitativos y que, además, cuando esta se les infligió, no fue «tanto debido ao seu desempeño profesional docente, canto por seren cidadáns activos en defensa da legalidade republicana». ${ }^{4}$ En efecto, en este juego trágico de suma cero implantado por los franquistas, el peso más oneroso recayó sobre aquellos docentes que habían mostrado, a través de su militancia político-ideológica, un compromiso manifiesto, especialmente durante el período republicano, con el viejo ideal de hacer de la escuela, a la par de un foco activo y útil de instrucción, uno de los motores cardinales de transformación de la sociedad. Del grueso de esta fracción de profesores militantes —numéricamente muy menor en relación con el total- procederá el núcleo de las víctimas de las actuaciones suma-

\footnotetext{
${ }^{3}$ Antonio Somoza Cayado, Andrés Domínguez Almansa y Lorenzo Fernández Prieto, «La génesis del Régimen franquista en Galicia: aniquilación política y destrucción de la sociedad civil (19361939)», en La dictadura franquista: la institucionalització d'un régim, dirs. Antoni Segura, Andreu Mayayo y Teresa Abelló (Barcelona: Publicacions i Edicions de la Universitat de Barcelona, 2012), 53-68. Los datos indicados son la media aritmética que realicé a partir de los datos desagregados que se consignan en la publicación citada.

${ }^{4}$ Antón Costa Rico, «Os ensinantes galegos e o 36. Os mortos e os exiliados», en A II República e a Guerra Civil: actas dos traballos presentados ao II Congreso da Memoria, Culleredo, 1 a 3 de decembro de 2005, comp. Enrique Barrera et al. (s.l.: Asociación Cultural Memoria Histórica Democrática, 2006), 499.
} 
rias y de los reos de los procesos judiciales que los tribunales militares instruyeron y resolvieron, en decenas de ocasiones, con sentencias de muerte. Del mismo segmento de docentes se nutrirá el primer flujo de exiliados, aquellos que, bien inmediatamente después del golpe de Estado, bien tras permanecer escondidos o fugados durante cierto tiempo, huyeron al advertir que la permanencia en territorio gallego conllevaría para ellos un riesgo inminente e inequívoco de prisión e incluso de muerte. Es por tal motivo que algunos ejemplos de estas huidas clandestinas sirvieron después para construir el referente icónico del exilio gallego, como fueron el de la azarosa y terrible vivencia, no exenta de abundantes pasajes novelescos, del maestro Antón Hipólito Alonso Ríos, o los de los también maestros Luís Bazal Rodríguez, Isidoro Cid Rivo o Luís Soto Fernández, entre otros.

En cualquier caso, conviene regresar al concepto de estado de cuarentena aludido anteriormente, pues no se debe olvidar que prácticamente todos los docentes, para poder seguir ejerciendo la profesión en Galicia, se verían obligados a someterse a una prueba de aptitud, que no habrían de realizar ellos mismos sino las nuevas autoridades por medio de los procedimientos administrativos que se encargarían de instruir las comisiones depuradoras provinciales, creadas ad hoc a partir de septiembre de 1936. Los dictámenes finales de las comisiones dimanarían, en la mayor parte de las instrucciones, de los informes igualmente arbitrarios solicitados al alcalde, al párroco, al puesto de la Guardia Civil o a una persona de solvencia ideológica del lugar en el que ejercía el docente objeto de la investigación. ${ }^{5}$ En dichos informes era preciso responder a preguntas concretas, formuladas en el escrito de solicitud de la comisión, en las que se ponían de manifiesto, además de las aptitudes requeridas a los docentes, los fundamentos en los que se habría de sustentar el edificio en construcción del nuevo sistema educativo español. Un naciente modelo en el que no habrían de quedar vestigios de la enseñanza republicana y tampoco de la que había representado la ya antigua tradición de la Escuela Nueva:

\footnotetext{
${ }^{5}$ Olegario Negrín Fajardo, «La depuración franquista del profesorado en los institutos de segunda enseñanza de España (1937-1943). Estudio cuantitativo para Galicia», Sarmiento. Anuario Galego de Historia da Educación 10 (2006): 66. También Lucio Martínez Pereda, «La depuración franquista del Instituto de Vigo: una primera aproximación», Glaucopis. Boletín del Instituto de Estudios Vigueses 14 (2008/2009): 184-195.
} 
Como presidente de esta comisión [...] requiero a V. [...] se sirva informar a esta Comisión acerca de los siguientes extremos, relativos a los Maestros que, en 18 de Julio 1936, estaban al frente de las Escuelas Nacionales pertenecientes a ese Ayuntamiento.

1. ${ }^{\circ}$ Conducta profesional, es decir: [...] Si las enseñanzas que dan se inspiran en los dictados de un fervoroso amor a España. Si inculcaba o inculca a sus alumnos el respeto a las Instituciones básicas de nuestra civilización, tales como la Patria, la familia, la propiedad, la jerarquía de las clases sociales, etc. Si se mostraba y se muestra hostil a ellas o indiferente. Si hacía labor religiosa, etc. ${ }^{6}$

Este proceso general abierto a los docentes en Galicia implicaría, finalmente, para un considerable número de ellos, la asunción de sanciones administrativas de diverso tipo y grado, incluida la inhabilitación permanente. Estos docentes conformaron lo que, en un empeño taxonómico, se puede denominar un segundo modelo de exilio: el de aquellos que, tras salir de prisión o ser objeto de alguna sanción más o menos gravosa, deciden marcharse, no siempre por medio de una vía clandestina o ilegal, al percibir que la permanencia en la comunidad de pertenencia significaba inexorablemente una existencia enajenante, problemática o sin horizonte. Durante toda la Guerra Civil e incluso mucho después de terminada esta, tomarían el camino del exilio algunos docentes sancionados o expresidiarios, como José Viéitez de Soto, que lo haría en 1946 luego de penar en múltiples cárceles, y su esposa, la también maestra Carmen Gómez Martínez, que logrará reunirse con él, en México, dos años más tarde.

\section{EL EXILIO GALLEGO DE 1936}

El exilio gallego carece de una imagen que le sirva de icono representativo específico semejante a aquellas que reproducen una legión de hombres, mujeres y niños cruzando los Pirineos y que, con tanta fre-

\footnotetext{
${ }^{6}$ Guerra civil (1936-1939) e literatura galega (textos e documentos para unhas xornadas de estudio e debate), eds. Xesús Alonso Montero y Miro Villar (Santiago de Compostela: Consello da Cultura Galega, 1999), 21-22.
} 
cuencia, sirvieron hasta hoy para poner en escena el drama del éxodo republicano español de 1939 en su conjunto. Tampoco resultan válidas para este fin, en buena medida, las fotografías de los vapores atestados de personas que zarparon desde España o más tarde desde Francia con destino a distintos países del mundo, y que tantas veces ilustraron muchas de las cubiertas y páginas de las publicaciones que abordaron este hecho histórico. Y no lo son, por lo menos en parte, porque, en el caso de Galicia, una variada combinación de factores y circunstancias peculiares operaron a modo de coyuntura determinante que hizo de su exilio, si atendemos a muchos de sus elementos característicos, un fenómeno ciertamente singular - pero en ningún caso contrapuesto- en relación con otros exilios hispánicos.

Supuso un factor decisivo el hecho ya referido de que, de forma rápida, casi todo el territorio gallego quedó bajo el control y la autoridad de los militares golpistas. Además, a la condición de territorio ocupado y de retaguardia bélica, se sumó la fatal circunstancia de la práctica inexistencia de vías de escape más o menos porosas a través de las cuales pudieran huir las personas que, en el momento que fuese, tuvieron o percibieron la necesidad de hacerlo. De hecho, ya antes de terminar el mes de julio de 1936, Galicia era una auténtica jaula en la que cualquier tentativa de fuga resultaría muy dificultosa y arriesgada. No en vano, a Galicia la cercaban por el norte y el oeste un mar que se disputaban las dos facciones en conflicto; por el sur, el Portugal del dictador profranquista António de Oliveira Salazar — desde donde fueron habituales las deportaciones- y, por el este, una frontera de orografía muy abrupta lindante con territorios también ocupados por los insurgentes, salvo la asturiana durante un breve período de tiempo. Un escenario tan hostil hará que, en multitud de ocasiones, los intentos de fuga acabasen en fracaso y, consecuentemente, en el encarcelamiento o el asesinato de los desdichados aspirantes al premio de la libertad. Uno de estos lances trágicos fue el que protagonizaron los maestros José Losada Castelao y Manuel Rodríguez Castelao — ambos primos de Alfonso Castelao-, quienes, tras permanecer más de un año escondidos, encuentran, en abril de 1937, la que era para ellos la oportunidad de huir. Sin embargo, como consecuencia de una delación, el día 23 son sorprendidos, junto a otros cinco hombres y el matrimonio formado por Carmen Miguel Agra y Ángel Nogueira Nogueira, dentro del bou Eva cuando estaban a punto 
de zarpar del puerto de O Berbés de Vigo. Después de un prolongado acoso y del intento de hundimiento de la embarcación por parte de los militares, los nueve fugitivos toman la decisión de suicidarse, valiéndose para este macabro fin de la única arma de fuego que poseían. ${ }^{7}$

Así pues, los exiliados y exiliadas procedentes de Galicia no conformaron nunca una masa ordenada, ni dispusieron en su huida del auxilio de instituciones gubernamentales, organizaciones políticas o comités de apoyo, a diferencia de sus hermanos de sino de Cataluña, Euskadi o de otros lugares de la zona republicana. Contaron a lo sumo con su propia determinación e inteligencia, y con la ayuda que les dispensaron familiares, amigos o, en contados casos, la propia guerrilla. También encontraron socorro, en multitud de ocasiones, en personas ajenas a su entorno social y geográfico más próximo, movidas por un aliento humanitario o de afinidad ideológica, como ocurrió tantas veces con ciudadanos portugueses, con quienes resultaron operativas las históricas relaciones culturales, económicas y migratorias existentes entre ambas comunidades, y que harían, por ende, de Portugal tanto un lugar de refugio temporal como una de las vías de tránsito más permeables de entre las pocas disponibles, a pesar del celo diligente que la Guarda de Fronteiras y la Polícia de Vigilância e Defensa do Estado mostrarían en la labor a ellas encomendada de custodiar la larga frontera con Galicia y de localizar a los republicanos españoles que se hubiesen adentrado en territorio luso. La relevancia de Portugal en el éxodo republicano gallego hizo que surgiesen algunas tentativas de influir positivamente en la actitud hostil del Gobierno portugués, más testimoniales que eficaces a tenor de su naturaleza y de sus nulos resultados, lo que, a su vez, explicita la situación de desamparo a la que se vieron sojuzgados los exiliados gallegos. Así, en 1937, los diputados galleguistas Alfonso Castelao y Ramón Suárez Picallo firman la «Carta a Oliveira Salazar, ditador de Portugal», que la delegación en el exilio del Frente Popular portugués editará en Madrid y difundirá clandestinamente en Portugal, más que con el ánimo de influir en la voluntad del dictador luso, con el fin de alentar a la población portuguesa a socorrer a los desvalidos fugiti-

\footnotetext{
${ }^{7}$ Xesús Alonso Montero, "Paz Andrade, poeta do bou "Eva”", La Voz de Galicia, 28 de abril de 2012. Puede accederse al testimonio de una de las hijas del matrimonio citado a través del documental Flores tristes, de Manuel Teo Abad (2008). En este filme también se refiere, entre otros casos de tortura, la infligida al maestro Arximiro Rico, asesinado en 1937.
} 
vos gallegos. Así mismo, en fechas próximas, prófugos en territorio portugués, "humildes gentes de Galicia [obligadas] a llevar una vida absolutamente indigna», le enviarán otra epístola, en este caso anónima, al mismo destinatario, presidente del Estado Novo, en estos términos:

[...] No pretendemos en modo alguno burlar las leyes de Portugal, ni tampoco forzar su hostilidad. Si su Excelencia juzga que somos agentes peligrosos de propaganda política, razón por la cual no podemos residir en esta nación hermana, autorícenos el embarque libremente para otros países, o reclúyanos en un campo de concentración, con gastos de sostenimiento por nuestra cuenta. Si no podemos vivir en Portugal, déjenos su Excelencia libertad para abandonarlo. Es cuanto respetuosamente le pedimos. ${ }^{8}$

De esta coyuntura general se derivaron efectos considerables, como lo fue el hecho de que el número absoluto de exiliados gallegos —en torno a los 2300, incluyendo los que se encontraban accidentalmente o con carácter permanente, en julio de 1936, en territorios en donde no triunfó la insurrección- representó finalmente una proporción ciertamente menor en relación con la totalidad de los exiliados republicanos españoles. ${ }^{9}$ Coherentemente y por las mismas razones, tampoco el exilio gallego siguió lo que podría denominarse un patrón de actuación más o menos fijo o paradigmático fácil de tipificar, salvo en lo concerniente a los destinos de preferencia, como se verá más adelante. ${ }^{10}$ Sea como fuere, para este propósito clasificador puede resultar útil, por su particularidad aglutinadora, el relato de las amargas vicisitudes padecidas por una única familia, la formada por Telmo Bernárdez Santomé, Isabel Gómez Costas y sus ocho hijos, de los cuales Isabel, Jesús

\footnotetext{
${ }^{8}$ Alberto Pena Rodríguez, «Galeguismo, franquismo e salazarismo. A colonia e os intelectuais galegos en Portugal durante a Guerra Civil española», en Os exilios ibéricos: unha ollada comparada. Nos 70 anos da fundación do Consello de Galiza, eds. Ramón Villares y Xosé M. Núñez Seixas (Santiago de Compostela: Consello da Cultura Galega, 2017), 378.

${ }^{9}$ La cifra es aproximada y parte de la aportada (2255), hace ya más de dos décadas —y que, por ello, consideramos incompleta-, en Repertorio biobibliográfico do exilio galego: unha achega [CD] (Santiago de Compostela: Consello da Cultura Galega, 2006).

${ }^{10}$ La ardua tarea de tipificación del exilio gallego la realizó Xosé M. Núñez Seixas en el capítulo tercero de su libro $O$ soño da Galiza ideal. Estudos sobre exiliados e emigrantes galegos (Vigo: Editorial Galaxia, 2016), 69-125. Seguí hasta el momento y seguiré en adelante las propuestas de este historiador en esta cuestión.
} 
y Telmo eran maestros. En julio de 1936, el padre, médico de profesión, es detenido en su casa familiar en Redondela, acusado de haber participado en el comité de huelga local organizado a raíz del golpe de Estado, para ser, posteriormente, juzgado en consejo de guerra y fusilado. ${ }^{11} \mathrm{Con}$ él, son también detenidos sus hijos Telmo y Jesús, ambos militantes de Izquierda Republicana. Empujadas por los trágicos acontecimientos, la madre y sus seis hijas, entre las que se encontraba la maestra Isabel Bernárdez Gómez, inician la huida, primero a Oporto y Burdeos, donde permanecen hasta la entrada de las tropas nazis en París, y más tarde, vía Nueva York, a México. En su capital federal las esperaba Jesús, quien había arribado al país poco antes, el 7 de julio de 1939, a bordo del vapor Ipanema, tras vivir un periplo igual de azaroso que había tenido su comienzo cuando consigue escapar de la cárcel a las pocas semanas de ser detenido. Huye entonces a Oporto, luego a Francia en un barco con bandera noruega, y allí decide viajar a la España republicana para luchar en el frente de guerra como soldado. Antes de llegar a México, aún habría de tener que franquear la frontera con Francia y sobrellevar su internamiento en el campo de reclusión de Argelès-sur-Mer. ${ }^{12}$ El reagrupamiento familiar definitivo en México tendría lugar aún en 1940, cuando el otro maestro de la familia, Telmo, es liberado de la cárcel al serle revisada la condena a cadena perpetua a la que un tribunal militar lo había sentenciado por rebelión. ${ }^{13}$

El nombre de Jesús Bernárdez Gómez puede servirnos, además, de hilo conductor para acometer el exilio de los docentes que, en su huida desde Galicia, en vez de salir definitivamente de la península ibérica y asentarse en otros países —como Xosé Núñez Búa, Concepción Álvarez Pazo y un largo etcétera-, entraron, por voluntad propia o por la falta de una mejor opción, en territorio republicano, comúnmente desde Portugal o Francia, pero también utilizando otras vías. Fue uno de estos casos el de Ramón de Valenzuela Otero, quien, estando en libertad

\footnotetext{
${ }^{11}$ Carlos Fernández Santander, Alzamiento y guerra civil en Galicia (1936-1939) (Sada: Ediciós do Castro, 2000), 304. Tomo I

12 Cátedra del Exilio. Proyecto «Exiliados en México. Política y sociabilidad», «Jesús Bernárdez Gómez», Centro de Investigaciones Históricas de la Democracia Española de la UNED. http://exiliadosmexico.blogspot.com.es/2012/09/climent-beltran-juan-bautista.html (consultado el 2-11-2017).

${ }_{13}$ Proyecto de investigación «Nomes e Voces», «Telmo Bernárdez Gómez», Universidade da Coruña, Universidade de Santiago de Compostela y Universidade de Vigo. http://vitimas.nomesevoces. net/gl/ficha/743/ (consultado el 2-11-2017).
} 
después de sufrir un breve encarcelamiento, se alista en el ejército franquista no tanto con el objeto de zafarse de una subyugante situación de acoso y sospecha - una alternativa, por otra parte, a la que numerosos represaliados se aferraron a modo de conducto a través del cual congraciarse con las nuevas autoridades-, cuanto con la intención de pasarse al bando republicano en el momento en que surgiese la ocasión propicia. Esta le llegaría y la aprovecharía con éxito Ramón de Valenzuela en septiembre de 1938, cuando se encontraba en el frente de guerra extremeño. Meses atrás, también por Extremadura, pero a través de su frontera con Portugal, había logrado igualmente introducirse en territorio republicano el, hasta julio de 1936, presidente de la Asociación de Trabajadores de la Enseñanza de Orense (ATEO) — ligada a la FETE-UGT-, Luís Soto Fernández, gracias a la intervención eficaz del Socorro Rojo Internacional. ${ }^{14}$

A partir de entonces, la trayectoria personal de estos exiliados correrá pareja con la de aquellos que, en julio de 1936, se encontraban en zonas en las que el golpe de Estado no había triunfado, fuese accidentalmente, como el ejemplo ya aludido de Castelao, fuese porque se hallaban ya asentados en ellas, como el maestro de formación, exmisionero pedagógico e intelectual Rafael Dieste. Una suerte, la de unos y otros, que habría de ser tanto menos borrascosa en el futuro cuanto más vinculada hubiese estado su actividad durante el conflicto bélico a grupos que ocupaban posiciones dominantes en el tablero político y cultural de la República en guerra, pero entre los que no existirá ninguna opción autónoma específicamente gallega, de naturaleza política o de otra índole, lo suficientemente bien situada para influir a favor de los exiliados gallegos atendiendo a su origen. Esta situación de desvalimiento se hará especialmente patente cuando tiene lugar el colapso militar republicano, ya que los exiliados gallegos no podrán beneficiarse entonces de algo análogo a un Entr'aide aux Républicains Catalans, constituído, en Perpiñán, el 3 de febrero de 1939 «para facilitar asistencia material a los refugiados [catalanes] que careciesen de lo más indispensable»; ${ }^{15}$ o de un Comité Pro-Inmigración Vasca en Argentina, que

\footnotetext{
${ }^{14}$ Xurxo Martínez González, Luís Soto: a xeira pola unidade galega (Vigo: Edicións Xerais de Galicia, 2011), 59.

15 Ángel Duarte, “"Dolça Catalunya. Patria del meu cor!”. Glosas al exilio catalanista de primera hora», en Os exilios ibéricos, 342.
} 
formó parte de toda una red de numerosas «instituciones, asociaciones y grupos de presión internacionales diferenciados para la protección de los exiliados vascos». ${ }^{16}$ El Partido Galleguista, que estaba llamado a desarrollar este tour de force, no sabría o no podría ocupar, dada su debilidad política, tal posición estratégica en esa partida jugada a la desesperada, incluso para beneficio de sus propios militantes, cuestión no baladí que ha sido señalada por Ramón Villares:

O exilio republicano vinculado ao Partido Galeguista non se beneficiou das axudas que, a través de organizacións como o Servicio de Evacuación de Exiliados Españoles (SERE) ou a Junta de Auxilio a los Republicanos Españoles (JARE), sufragaron viaxes e primeiras necesidades dos milleiros de refuxiados que lograron viaxar nos barcos fretados desde Francia cara a diversos países de América [...]. Dos poucos militantes (non máis de dúas ducias) do «Grupo Galeguista» [...] resulta que, agás o caso atípico de Castelao e de Guerra da Cal, que saíron en misión oficial en 1938, os demais seguiron as rutas clásicas do exilio americano canda os republicanos. ${ }^{17}$

De esas «no más de dos docenas» de exiliados galleguistas, algunos nombres pertenecían a docentes. En la órbita del Partido Galleguista estaban el catedrático de instituto Ramón Martínez López o los jóvenes profesores universitarios Luís Tobío Fernández y Xoán López Durá. Con ellos, alrededor de medio centenar más de docentes gallegos no adscritos al galleguismo que habían pasado la guerra en territorio republicano acabarán pudiendo aprovecharse de las acciones de evacuación oficiales. Sin embargo, ¿cuántos pudieron llegar a hacerlo de los que integraban el contingente de 1320 gallegos identificados actualmente que aún permanecían en los campos de reclusión franceses a finales de 1939?: ${ }^{18}$ ¿y cuántos de los que no lo lograron terminaron siendo deportados a la España de Franco o a los campos de concentración nazis? En el de Mauthausen internarían, en agosto de 1940, al catedrático de ins-

\footnotetext{
${ }^{16}$ Óscar Álvarez Gila, «¿Exilio vasco, exilios vascos? Imágenes y debates entre la historia y la memoria», en Os exilios ibéricos, 303.

17 Ramón Villares, «O Consello de Galiza na estratexia dos exilios ibéricos, 1939-1950», en Os exilios ibéricos, 23.

${ }^{18}$ Núñez Seixas, O soño da Galiza ideal, 95.
} 
tituto Juan González del Valle, quien, meses después, acabaría sus días en el castillo de Hartheim. ${ }^{19}$ Mientras tanto, el maestro Ramón de Valenzuela continuaba, por decisión propia, la lucha en Francia, hasta ser detenido, en 1941, por la Gestapo, deportado a España y encarcelado. Su nombre lo volveremos a encontrar una vez más cuando hablemos del exilio gallego en Argentina.

\section{«TODA A TERRA É DOS HOMES»: DESTINOS E INSERCIÓN LABORAL}

En 1944, Alfonso Daniel Rodríguez Castelao le escribía una carta, desde Buenos Aires, a José Antonio Aguirre, presidente del Gobierno Vasco en el exilio, en la que se lamentaba de que «la flor del pueblo gallego no ha podido huir».$^{20}$ Ciertamente, ese había sido el reverso de la tragedia vivida por una parte sustancial de la sociedad gallega, de cuya magnitud dan cuenta los datos cuantitativos referidos al ámbito de la docencia, extrapolables, en buena medida, a los restantes sectores profesionales. Sobre algo menos de un centenar de docentes gallegos se encontraban, en 1941, en el exilio y, de ellos, alrededor del $75 \%$ pertenecían al grupo de los que se hallaban en lugares en donde el golpe de Estado no había prosperado o estaban fuera de España. ${ }^{21}$ La exigua veintena restante la integraban maestros y profesores a los que el levantamiento militar había sorprendido en Galicia y habían logrado fugarse. ${ }^{22}$ Estos datos hablan por sí solos de la magnitud de la tragedia, especialmente si se tiene en cuenta, como indica Xosé Manuel Cid Fernández, que «De la cifra citada de muertos [3.000], unos 100 eran educadores; otros 700 fueran separados de la enseñanza y unos dos mil con algún tipo de pena administrativa y económica (más

\footnotetext{
19 Proyecto de investigación «Nomes e Voces», «Juan González del Valle», Universidade da Coruña, Universidade de Santiago de Compostela y Universidade de Vigo. http://vitimas.nomesevoces.net/ gl/ficha/5050/ (consultado el 4-11-2017).

${ }^{20}$ Cito por Ramón Villares, «O Consello de Galiza na estratexia dos exilios ibéricos, 1939-1950», en Os exilios ibéricos, 24.

${ }^{21}$ Los datos proceden fundamentalmente - pero no solo- de dos fuentes ya citadas: Repertorio biobibliográfico y Antón Costa Rico, «Os ensinantes galegos e o 36. Os mortos e os exiliados».

${ }_{22}$ Como contrapunto ilustrativo del caso gallego pueden servir los 387 maestros catalanes exiliados que consigna el profesor Salomó Marquès en L'exili dels Mestres (1939-1975) (Girona: Universitat de Girona-Llibres del Segle, 1995), 39.
} 
del 25\%)». ${ }^{23}$ Parecido patrón se repetirá en la Universidad de Santiago de Compostela, en donde la acción represiva afectó a 24 de sus 150 profesores $(16 \%)$, pero solo seis de ellos se marcharán al exilio. ${ }^{24}$

El continente americano fue el destino de preferencia de los docentes que, encontrándose el 20 de julio de 1936 en Galicia, consiguieron huir de la represión, si se exceptúa la pequeña fracción de los que, por propia voluntad o porque no tuvieron otra alternativa de fuga, entraron en territorio republicano. Así pues, a diferencia de otros exilios republicanos hispánicos, en los que la opción americana fue fruto de un apremio de última hora, el gallego optó por buscar cobijo en América desde el primer momento. No obstante, aquel temprano contingente se concentró únicamente en Argentina, en Cuba y, en mucha menor medida, en Uruguay. De hecho, no existe constancia de la llegada de docentes a ningún otro lugar de América distinto a estos tres entre 1936 y $1937 .{ }^{25}$ Que esta avanzadilla se dirigiese exclusivamente hacia estos países encuentra su explicación en motivos relacionados con las intensas corrientes migratorias preexistentes. Entre 1835 y 1936, sobre algo más de un millón y medio de gallegos y gallegas habían salido hacia el continente americano, con un flujo neto estimado de entre $620.000 \mathrm{y}$ 860.000 personas. ${ }^{26}$ Este movimiento migratorio había tenido, precisamente, a Cuba y a Argentina como principales lugares de destino. Ambos países, como más reducidamente también Uruguay, acogían en 1936 una muy nutrida comunidad gallega a la que, por otro lado, mu-

\footnotetext{
${ }^{23}$ Xosé Manuel Cid Fernández, «Represión injustificada en la retaguardia franquista. Las víctimas de la Asociación de Trabajadores de la Enseñanza de Ourense», en Entre el olvido y la memoria. Educación, mitos y realidades, ed. Teresa González Pérez (Valencia: Tirant Humanidades, 2018), 106.

${ }^{24}$ Ricardo Gurriarán, Ciencia e conciencia na Universidade de Santiago de Compostela (1900-1940). Do influxo institucionista e a JAE á depuración do profesorado (Santiago de Compostela: Servizo de Publicacións e Intercambio Científico da Universidade de Santiago de Compostela, 2006), 590-591. Siguiendo a este autor, estos fueron los profesores de la Universidad de Santiago de Compostela que se exiliaron: Fernando Calvet Prats (durante breve tiempo), Antonio Baltar Domínguez, Sebastián González García-Paz, Juan López Durá, Ernesto Seijo Espiñeira y Leoncio Virgós Guillén (quien, como Calvet, no era natural de Galicia). Así pues, se debe entender a partir de ahora que los profesores universitarios de origen gallego distintos a estos que se mencionen en las páginas sucesivas ejercían la docencia en otras universidades españolas o de Europa.

${ }^{25}$ El profesor de la Escuela Normal de Barcelona Hernán Poza Juncal, que se encontraba en 1937 en los EE.UU. constituye un caso anómalo, dilucidable tal vez por su militancia en el derechista Partido Republicano Radical.

${ }^{26}$ Alexandre Vázquez González, Emigrantes galegos, trasnsportes e remesas (1830-1930) (s.l.: Consello da Cultura Galega / Fundación Barrié, 2015), 75.
} 
chos de aquellos exiliados — docentes o no- que llegaban huyendo del terror en los primeros años de la guerra $-\mathrm{y}$ también los que llegarían después- se sentían unidos por variados lazos o incluso integrantes de ella, como oportunamente ha resaltado Xosé M. Núñez Seixas:

En varios casos, ademais, os exiliados xa eran persoas cunha ampla experiencia vital de mobilidade xeográfica, pois eles mesmos foran integrantes denantes da Guerra Civil, e adoito debían a esa primeira socialización laboral e política en América o seu compromiso político e ideolóxico posterior. [...] Por esa razón, algúns deles tamén tenderon a volver a América. Outros eran fillos de familias que migraran, e varios deles naceran alén mar, [...] conservando en máis dun caso a cidadanía dos países onde viran a primeira luz.

A Argentina arribaron un total de 24 docentes, de los cuales diez lo hicieron durante la guerra, otros nueve, inmediatamente después de la derrota militar republicana, y cinco, en años muy posteriores. ${ }^{27} \mathrm{Su}$ entrada resultaría en todo momento una empresa intrincada y ardua, con independencia del instante en el cual se produjese. De hecho, los sucesivos gobiernos argentinos, formalmente democráticos pero de naturaleza conservadora y autoritaria, se manifestarían abiertamente refractarios a su acogida por motivos ideológicos, una coyuntura que se prolongaría en el tiempo indefinidamente. No obstante, la respuesta tanto popular como, en concreto, del colectivo de emigrantes a la encrucijada de la contienda bélica en España sería inequívocamente favorable a la causa republicana, si bien la comunidad argentina en su conjunto experimentaría una clara polarización, fruto de la implantación

\footnotetext{
${ }^{27}$ Lo hicieron durante la guerra: Antón Alonso Ríos, Antonio Baltar Domínguez, Bieito Cupeiro Vázquez, Antonio Fernández Pérez, Concepción Fernández Vázquez, Xosé Núñez Búa, Gumersindo Sánchez Guisande, Antonio Rey Vázquez, Virgilio Trabazo Serapio y Leoncio Virgós Guillén; tras la derrota militar republicana: Augusto Barcia Trelles, Alfonso Díaz Trigo, Rafael Dieste González, Manuel Garrido González, Ramón Martínez López, Carmen Muñoz Manzano, José Higinio Otero Espasandín, Alfonso Daniel Rodríguez Castelao y Luciano Vidán Freiría; años después: Antonio González Blanco, Eladio Marcos Rodríguez, Carmen Santalla, Ramón de Valenzuela Otero y Alberto Vilanova Rodríguez. Incluimos en este último grupo a Antonio González y a Carmen Santalla, ambos militantes de Izquierda Republicana, porque el único dato que tenemos sobre ellos es que se encontraban, en Buenos Aires, en 1945. No incluimos en ninguno de los grupos ni computamos como exiliado, pese a haber acabado desterrado, al galleguista sui generis Álvaro María Casas Blanco, simpatizante de los golpistas.
} 
social en el país de las ideologías totalitarias europeas, y de los nada desdeñables esfuerzos del Gobierno de Burgos por influir en la opinión pública y en las instituciones de emigrantes. ${ }^{28} \mathrm{~A}$ favor de la República española actuarán múltiples entidades de naturaleza mutualista-asistencial, recreativa o simplemente étnica en las que se organizaba la comunidad de emigrantes gallegos. Muy sobresaliente sería, en este sentido, el papel representado por la Federación de Sociedades Gallegas de la República Argentina, fundada en 1921, y por su Comité de Ayuda al Gobierno Español del Frente Popular (también denominado Central Gallega), creado ya en 1936, al que la institución matriz destinará de forma casi íntegra, a partir de entonces, los fondos dinerarios propios y los de sus entidades federadas. ${ }^{29}$

En no pocas ocasiones, sin embargo, la obtención de los permisos de entrada y de un puesto de trabajo será posible gracias a la intervención de familiares, amigos o correligionarios. Uno de estos casos fue el del maestro José Otero Espasandín, quien, tras salir del campo de refugiados de Saint-Cyprien en febrero de 1939 y trasladarse inmediatamente a Gran Bretaña —donde lo esperaban, desde 1938, su hija y su esposa, la también maestra Alicia Ortiz Alonso-, logra arribar con toda la familia al puerto de Buenos Aires en marzo de 1941, merced a las eficaces gestiones llevadas a cabo, durante año y medio, por exiliados ya radicados en la ciudad. Residirá en la capital porteña cerca de seis años, hasta que en 1947 se traslada a los EE. UU. para ejercer de profesor en un instituto de un pueblecito del Estado de Pennsylvania. Durante su estancia en Buenos Aires trabajará en la editorial Atlántida, junto a los viejos amigos también exiliados Rafael Dieste y Carmen Muñoz — principales artífices de su entrada en Argentina-, y en ella protagonizará, como publicista, uno de los capítulos más heroicos que entre los obreros de la tinta y el papel se hayan dado nunca. ${ }^{30}$ En este sello editorial, concretamente en su Colección Oro de Cultura General, Espasandín llegará a

\footnotetext{
${ }^{28}$ Luis Velasco Martínez, «Fascismo de ultramar: la proyección del falangismo en la comunidad española del Río de la Plata (1936-1940)» (Memoria para optar al grado de licenciado, Universidad de Santiago de Compostela, 2015).

${ }^{29}$ Hernán M. Díaz, Historia de la Federación de Sociedades Gallegas: identidades políticas y prácticas militantes (Buenos Aires: Fundación Sotelo Blanco-Biblos, 2007), 89.

${ }^{30}$ Gregorio Ferreiro Fente, «Xosé Otero Espasandín: literatura e exilio», en Xosé Otero Espasandín, Obra galega, ed. María Cuquejo Enríquez (Santiago de Compostela: Centro Ramón Piñeiro para a Investigación en Humanidades-Xunta de Galicia, 2006), 30-36.
} 
publicar, hasta su partida a los EE.UU., 26 libros didácticos y de divulgación científica de temática variada, siguiendo cabalmente las exigencias marcadas por el director de la colección, el institucionista Rafael Dieste:

[...] un libro de divulgación que no exija para ser entendido conocimientos especiales ni más hábito literario que el de leer una revista no literaria. Sin embargo, el libro debe ser bonito, noble, como una conferencia de Misiones que pudiese escuchar con gusto cualquiera de los misioneros además del público. ${ }^{31}$

El ejemplo de José Otero Espasandín nos adentra en las actividades a las que se dedicaron, pro pane lucrando, los docentes exiliados una vez que se establecieron en Argentina. Aunque se desconoce cuál acabó siendo la ocupación fundamental en bastantes casos, se puede afirmar que la inserción laboral de la mayoría de ellos en el país fue a través de profesiones no ligadas a la enseñanza, con excepción de los profesores universitarios, pues casi todos estos, con menor o mayor dificultad, acabarán ingresando en universidades argentinas (Antonio Baltar Domínguez, Alfonso Díaz Trigo, ${ }^{32}$ Gumersindo Sánchez Guisande) o, posteriormente, de otros países, como los EE. UU. (Ramón Martínez López) o Chile (Celso Manuel Garrido González). ${ }^{33}$ El maestro Virgilio Trabazo Serapio trabajará en varios colegios católicos privados, Bieito Cupeiro Vázquez mantendrá cierta actividad docente durante algún tiempo, pero en cambio Antonio Pérez Fernández desarrollará actividades comerciales, Antonio Vázquez Rey se empleará en un banco, etc. Las causas de esta realidad tan poco favorable a que los docentes gallegos pudiesen continuar ejerciendo su profesión en Argentina radicarían, por una parte, en el hecho de que ni las instituciones republicanas ni el poco cohesionado colectivo de exiliados crearán escuelas destinadas a la escolarización de sus hijos, como sí se hizo en México y Cuba; y,

\footnotetext{
${ }^{31}$ Rafael Dieste, Obras completas, Tomo v: epistolario, ed. Xosé Luís Axeitos (Sada-A Coruña: Ediciós do Castro, 1995), 185.

32 Médico muy joven al estallar la guerra, Díaz Trigo no había ejercido la docencia universitaria previamente cuando llega a Argentina en 1939.

${ }^{33}$ No fue así en el caso del profesor de Química Inorgánica de la Universidad de Santiago de Compostela Leoncio Virgós Guillén, quien ejercerá de médico militar durante los escasos dos años que reside en Argentina, hasta que le sobreviene la muerte en noviembre de 1938.
} 
por otra parte, en la circunstancia — que se repetirá en todos los países americanos - de que las numerosas instituciones societarias gallegas de emigrantes, cuya finalidad principal era de naturaleza asistencial y lúdica, carecían de centros educativos propios. En consecuencia, como afirma Bárbara Ortuño Martínez:

[...] una parte significativa optó por educar a sus hijas e hijos en la escuela pública, mientras que otra lo hizo en los centros privados pertenecientes a otras colectividades extranjeras, como la inglesa o la francesa. Esta decisión estuvo motivada en muchos casos por la afinidad que sentían tener con estas culturas, porque consideraban que ofrecían la mayor formación para cuando regresaran a Europa (sobre todo porque sus hijos recibían una educación bilingüe), y porque cuando se instauró el primer Gobierno de Perón en 1946, desde el punto de vista de muchos republicanos españoles, la calidad de la educación pública descendió y en ciertos aspectos entró en pugna con sus ideas. $^{34}$

Cuba fue, en términos cuantitativos, el segundo lugar de destino de los docentes que, fugados de Galicia tras la insurrección militar, buscaron asilo directo en América. En 1937, se encontraban en esta isla del Caribe siete docentes gallegos, cifra que se incrementará, una vez terminada la guerra, con la llegada de otros ocho más. ${ }^{35}$ Del mismo modo que en Argentina, la entrada y radicación en Cuba tampoco habría de ser una tarea cómoda para los exiliados republicanos, hacia quienes,

\footnotetext{
${ }^{34}$ Bárbara Ortuño Martínez, Hacia el hondo bajo fondo... Inmigrantes y exiliados en Buenos Aires tras la Guerra Civil española (Madrid: Biblioteca Nueva, 2018), 140.

${ }^{35}$ Llegaron durante la guerra: Xerardo Álvarez Gallego, José María Bourio Fernández, Sebastián González García-Paz, Ignacio Herrero Fuentes, Juan Martínez Buján, Jesús Mejuto Vázquez y Eduardo Pazo Álvarez; lo hicieron después de la derrota republicana: Pedro Antón García, Xosé Gómez Gayoso, Lino Novás Calvo, Xosé Rubia Barcia, Leonardo Santamarina Becerra, Arturo Souto Feijoo, Paulino Suárez, Lois Tobío Fernández y Jesús Vázquez Gayoso. No incluyo en esta relación al adolescente José Amor Vázquez, que estudiará, en la Universidad de La Habana, las carreras de Filosofía y Letras y de Derecho, y será después profesor universitario en los EE.UU.; ni a la niña Dora Carcaño Araújo, quien estudiará Magisterio en La Habana. Por otra parte, Jesús Mejuto Vázquez permanecería muy poco tiempo en Cuba, pues regresará a España para participar en la guerra en el bando republicano (Carlos Pereira Martínez, «A represión en Culleredo: unha aproximación inicial», en A represión franquista en Galicia: Actas dos traballos presentados ao Congreso da Memoria. Narón, 4 a 7 de decembro de 2003, comp. Enrique Barrera Beitia et al. (Narón: Asociación Cultural Memoria Histórica Democrática, 2005), 485-486).
} 
sobre todo hasta 1940, el Gobierno cubano, ideológicamente conservador, adoptará una tesitura de indisimulada $-\mathrm{y}$, por momentos, combativa- desafección, que, no obstante, tenderá a hacerse «más sensible y solidaria» con el paso del tiempo. ${ }^{36}$ En contraposición con la actitud gubernamental, las clases populares cubanas, conformadas en más de un $10 \%$ por individuos de procedencia española, simpatizarán de modo manifiesto con el bando republicano, una toma de partido que quedaría evidenciada en el dato aportado por algunos estudiosos, según el cual algo más de la mitad de los voluntarios hispanoamericanos que lucharon como brigadistas o milicianos en la Guerra Civil procedía de Cuba. ${ }^{37}$ Por todas estas razones, resulta fácil comprender por qué el territorio cubano se acabó convirtiendo en un propicio campo de operaciones para el desarrollo de acciones de propaganda y de recaudación de fondos a favor de la República — como también del bando rebeldedurante el período bélico, al que concurrirán figuras gallegas y españolas del ámbito de la cultura y la política republicanas, enviadas al país en misión oficial. Con tal propósito, Alfonso R. Castelao, acompañado del maestro Luís Soto Fernández, arribará, en noviembre de 1938, a la isla y la recorrerá incansablemente en una gira de clara intención política que durará hasta finales de febrero de 1939. Al poco de llegar, el 4 de diciembre, participará en un mitin —en el que también hablarán Félix Gordón Ordás, embajador de la República española en Cuba, y Luís Soto Fernández-, al cual asisten, según algunas crónicas del momento, cerca de 30.000 personas, ${ }^{38}$ lo que revela tanto el impacto que la contienda española había causado en la isla, como el grado de adhesión de sus ciudadanos a la causa republicana.

En Cuba, a Castelao también se le encomendará la difícil empresa de cooperar, haciendo valer su prestigio y carisma, con la Hermandad Gallega en su pugna interna con el grupo Afirmación Gallega, la facción profranquista, liderada por viejos y adinerados emigrantes gallegos de

\footnotetext{
36 Jorge Domingo Cuadriello, El exilio republicano español en Cuba (Madrid: Siglo XXI, 2009), 41. Esta extensa y muy documentada obra constituye una referencia insoslayable para ahondar en el conocimiento del tema que nos ocupa, por lo que me serviré de ella como fuente primordial, pero no única, en la redacción de este apartado dedicado a Cuba.

${ }^{37}$ Fernando Vera Jiménez, «Cubanos en la Guerra Civil española. La presencia de voluntarios en las Brigadas Internacionales y el Ejército Popular de la República», Revista Complutense de Historia de América 25 (1999): 319.
}

${ }^{38}$ Xurxo Martínez González, Luís Soto: a xeira pola unidade galega, 80. 
pensamiento muy conservador, que gobernaba el muy influyente Centro Gallego de La Habana. En esta misma tarea despuntaría el maestro y abogado Xerardo Álvarez Gallego, un exiliado de primera hora que presidía Hermandad Gallega desde su constitución, en agosto de 1938, y dirigirá, al crearse en diciembre de ese año, su órgano oficial de expresión, la revista de significativo nombre Loita, en cuyas páginas tendrían cabida abundantes textos en lengua gallega, inclusive de carácter literario. ${ }^{39}$ Durante aquellos años de lucha antifranquista, este sincero republicano y militante galleguista colaborará, además, como articulista, en el diario Luz y dirigirá la revista antifranquista Nosotros, ${ }^{40}$ portavoz de la Casa de la Cultura, asociación instituida en enero de 1938 que aglutinó «los sectores más radicales dentro del heterogéneo conjunto de partidarios de la República». ${ }^{41}$ Este exiliado, cuya familia había sido ferozmente golpeada por la represión desencadenada en Galicia, emprendía, de esta forma, la que, con el tiempo, habría de ser una destacada y dilatada carrera profesional como periodista hasta su partida de la isla en 1959.

Como Xerardo Álvarez Gallego, buena parte de los docentes gallegos llegados a Cuba trató de afincarse en la isla. Algunos incluso soñaron inicialmente con hacerlo dando continuidad a su profesión, una pretensión que adquirirá forma temporalmente con el surgimiento, en agosto de 1939, de la Escuela Libre de La Habana, un proyecto educativo que, amparado en el mecenazgo de la acaudalada rentista cubana María Luisa Gómez Mena, impulsaron conjuntamente docentes nativos y también exiliados, como los profesores universitarios gallegos Lois Tobío Fernández, Xesús Vázquez Gayoso y José Rubia Barcia, quien además crearía, integrando el plan de estudios del centro, la Academia de Artes Dramáticas. ${ }^{42}$ Inspirada en los principios de la Institución Libre de Enseñanza, la Escuela Libre de La Habana nacía con el objetivo de «rea-

\footnotetext{
${ }^{39}$ Loita: órgano de Hermandad Gallega [ed. facsimilar] (Santiago de Compostela: Centro Ramón Piñeiro para a Investigación en Humanidades, 1999).

${ }^{40}$ Diccionario biobibliográfico de los escritores, editoriales y revistas del exilio republicano de 1939, volumen I, eds. Manuel Aznar Soler y José-Ramón López García (Sevilla: Biblioteca del Exilio-Renacimiento, 2016), 111-112.

41 Jorge Domingo Cuadriello, El exilio republicano español en Cuba, 26.

42 Para conocer el periplo de este profesor tanto en Cuba como después en los EE.UU. resulta especialmente interesante la lectura del libro autobiográfico de José Rubia Barcia, Unha vida contada, ed. José Manuel González Herrán (Santiago de Compostela: Consello da Cultura Galega, 2014).
} 
lizar una renovación educacional dentro del ambiente amodorrado de los estudios por esa época», a la vez que servía para que los exiliados en la isla tuviesen "una forma viable de poder sobrevivir con decoro». ${ }^{43}$ No obstante, la Escuela pronto se revelará un proyecto económicamente inviable, al igual que otras empresas escolares de idéntica naturaleza que surgen por estas fechas y que acabarán, como aquella, cerrando sus puertas pocos cursos después de su apertura. Ejemplos de ello fueron la Academia Matemáticas, de la que fue docente el sacerdote jesuita gallego Pedro Antón García, y Estudios Generales de Ignacio Agramonte, con sede en Camagüey, en la que también impartirá clases José Rubia Barcia.

La difícil coyuntura económica por la que atravesaba la isla, a la que los sucesivos gobiernos intentaron dar solución con iniciativas legislativas proteccionistas muy lesivas para la integración laboral de las personas foráneas, y la actitud de prevención celosa que asumió parte del profesorado cubano, especialmente el universitario, ante sus colegas transterrados, serían factores añadidos que empujarían finalmente a muchos docentes gallegos a buscar refugio en otros países, lo que ha llevado justificadamente a muchos especialistas en la materia a considerar Cuba un destino de tránsito más que de radicación. Sin embargo, si se centra la mirada en el ejemplo de los docentes gallegos, dicha apreciación parece ser aplicable a aquellos en los que tal vez no había muerto el anhelo de proseguir desempeñando su profesión, y, con tal pretensión, toman la determinación de marcharse a otros países, casi siempre tras probar antes suerte en la isla: Sebastián González García-Paz, a Puerto Rico; Ignacio Herrero Fuentes, a Panamá y Venezuela; José Rubia Barcia y Leonardo Santamarina Becerra, a los EE.UU.; Arturo Souto Feijoo, a México; y Lois Tobío Fernández, a México (durante breve tiempo) y a Uruguay. Los restantes permanecieron e hicieron carrera, en Cuba, en los ámbitos artístico, periodístico e, incluso, académico, salvo el profesor de instituto José María Bourio Fernández, que se dedicaría al comercio de material de ferretería.

\footnotetext{
${ }^{43}$ Dania Vázquez Matos, «La Escuela Libre de La Habana: vivero de inquietudes y desvelos renovadores», en La Literatura y la Cultura del exilio republicano español de 1939: Actas del IV Coloquio Internacional (Alicante: Biblioteca Virtual Miguel de Cervantes, 2005), s/p. http://www.cervantesvirtual.com/nd/ark:/59851/bmckh0z4.
} 
De mucho menor atractivo que Argentina o Cuba resultó Uruguay como lugar de refugio para los exiliados gallegos, a pesar de ser un país en el cual, en 1936, tenía asiento una comunidad bastante numerosa de emigrantes originarios de Galicia que, a priori, podía actuar a modo de polo de atracción. El poco dinamismo socioeconómico de este país, así como las restrictivas políticas migratorias gubernamentales, muy similares a las argentinas, constituyeron factores que jugaron en sentido contrario a los intereses de los refugiados y de ahí que únicamente seis docentes se acabasen radicando en él con carácter más o menos permanente. ${ }^{44}$ El maestro Isidoro Cid Rivo llegaría a Uruguay en 1936 huyendo de la represión, y el profesor universitario y destacado investigador en el campo de la bioquímica Pedro Couceiro Corral lo haría en 1939, después de participar como soldado en las filas republicanas, siendo ambos los únicos ejemplos de docentes que eligieron este país como destino directo. Los cuatro restantes casos se establecerán en Uruguay bien tras reiterados tanteos en otros países o empujados por motivaciones familiares, bien, entrada ya la década de 1950, escapando de la represión de posguerra (Xerardo Díaz Fernández). Ninguna de estas personas se dedicará a la enseñanza, salvo, en cierto modo, la profesora de canto María Valverde y Juan García Durán.

Con base en argumentos que exceden los estrictamente cuantitativos, se ha insistido una y otra vez en la condición eminentemente mexicana del exilio republicano de 1939. Idéntica atribución es perfectamente asignable al exilio gallego si nos atenemos solo a los números y, en consonancia con ellos, México fue también el lugar de destino del mayor contingente de sus docentes. A México pondrán rumbo un total de 30 maestros y profesores de origen gallego, sirviéndose para hacer este viaje, fundamentalmente, de las distintas expediciones marítimas de evacuación oficial llevadas a cabo, desde Francia, durante 1939. ${ }^{45} \mathrm{Al}$

\footnotetext{
${ }^{44}$ Isidoro Cid Rivo, Pedro Couceiro Corral, Xerardo Díaz Fernández, Juan García Durán, Lois Tobío Fernández y María Valverde.

${ }^{45}$ Jesús Bal y Gay, los hermanos Isabel, Jesús y Telmo Bernárdez Gómez, María Bouzas Pérez, Concepción Castroviejo Blanco-Cicerón, Manuel Domínguez Benavides, Jesús Dopico Ferreiro, Bibiano Fernández Osorio-Tafall, Marcial Fernández Vázquez, Lorenzo García Méndez, Benito Guitián López, Ramón Iglesia Parga, Jacinta Landa Vaz, Xoán López Durá, Pedro Martul Rey, Alejandro Otero Fernández, Laureano Poza Juncal, Víctor Rico González, Joaquín Seijo Alonso, Luis Soto Fernández, Uxío Souto Campos, Arturo Souto Feijoo, los hermanos Carlos y María de los Ángeles Tobío Fernández, Carlos Velo Cobelas, Julio Vicente Sesto y Celso Vila Rodríguez. Llegan también a México, en años muy posteriores, el matrimonio de docentes José Viéitez de Soto (1946)
} 
amparo de las políticas de salvaguardia y acogida del gobierno del general Lázaro Cárdenas, que ya habían hecho posible su entrada en el país, y gracias a las acciones de las organizaciones de ayuda dependientes de las instituciones republicanas en el exilio, el profesorado gallego pronto encontrará un acomodo laboral, principalmente en tareas docentes, que le permitirá otear el futuro con cierto optimismo mientras barruntaba el momento del derrocamiento del régimen franquista. Los centros educativos creados bajo el patrocinio de las citadas organizaciones y, en ocasiones, de las propias autoridades gubernativas mexicanas con el objetivo de atender las necesidades educativas de la legión de hijos de la diáspora darían empleo, aunque fuese de forma transitoria y ciertamente precaria, a buena parte del magisterio gallego durante aquellos primeros años. Fundado en la ciudad de México a finales de 1939, el Instituto Hispano Mexicano Ruiz de Alarcón se convirtió en la institución educativa republicana en cuyas aulas impartirán clases un mayor número de maestros y profesores gallegos e, incluso, personas sin experiencia docente previa, como el médico Hermenegildo Losada Loureiro. La llamativa concurrencia de docentes de origen gallego en el claustro del Instituto tal vez encuentre explicación en el hecho de que su dirección estuvo a cargo del matrimonio formado por los también gallegos Ángeles Tobío Fernández y Pedro Martul Rey, responsables, a su vez, de hacer efectiva y viable una oferta educativa que comprendía todos los niveles no universitarios, incluyendo un jardín de infancia, que fue atendida tanto por maestros como por profesores de educación secundaria y universitarios. Integraron la amplia nómina de profesores gallegos del Instituto, entre posiblemente algunos más, Lois Tobío Fernández (durante muy breve tiempo) y su hermano Carlos, Jesús Bernárdez Gómez, Manuel Domínguez Benavides, Jesús Dopico Ferreiro, Marcial Fernández Vázquez, Jacinta Landa Vaz, Laureano Poza Juncal y Eugenio Souto Feijoo. En cualquier caso, la vida del Instituto Hispano

\footnotetext{
y Carmen Gómez Martínez (1948), y Concepción Pazo Álvarez (1946). No consigno en la relación al joven estudiante Carlos Caridad Mateo, que cursa estudios en México y más tarde será profesor en los EE.UU. Tampoco incluyo en la relación a Lois Tobío Fernández, quien, procedente de Cuba, residirá e impartirá clases durante meses en México antes de establecerse definitivamente en Uruguay. Se considera gallega a la extremeña - y hermana del institucionista Rubén Landa, también exiliado- Jacinta Landa Vaz (como páginas arriba, a la también extremeña Carmen Muñoz Manzano, casada con Rafael Dieste) no por su origen, sino por sus lazos con Galicia, fruto de su matrimonio con el pedagogo y político galleguista Xoán Vicente Viqueira: los hijos del matrimonio, Luisa, Carmen y Jacinto Viqueira Landa, también exiliados, ejercerán la docencia en México.
} 
Mexicano Ruiz de Alarcón acabaría siendo muy corta, de forma que, después de permanecer abierto durante cuatro agitados cursos escolares, cerrará sus aulas en 1943, un acontecimiento al que no fue ajena la pugna mantenida entre el SERE y la JARE, o, lo que es lo mismo, «la polémica entre dos socialistas adversarios, Indalecio Prieto y Juan Negrín, [que] estuvo en el fondo de la clausura del Instituto y la fundación del Colegio Madrid». ${ }^{46}$ Es muy probable que detrás de estas hostilidades se hallen las causas de la práctica ausencia de docentes gallegos en el Colegio Madrid, otra más de las instituciones educativas fundadas en el Distrito Federal al amparo de los organismos republicanos, en el que ejercerán Jesús Bernárdez Gómez en aquella etapa embrionaria y, ya a partir de 1946, Concepción Pazo Álvarez. Exigua sería también la presencia de docentes gallegos en el Instituto Luis Vives-Colegio Español de México, de cuyo claustro formarán parte, desde que se funda el centro a iniciativa del SERE en agosto de 1939, Lorenzo García Méndez, Luís Soto Fernández, Arturo Souto Feijoo y Luisa Viqueira Landa. Víctimas de condiciones laborales precarias y de los bajos sueldos, en el futuro la inserción laboral de muchos de estos docentes, en particular de los maestros, sería a través de profesiones desligadas de la enseñanza (empresarios o representantes de la industria química y farmacéutica, viajantes de comercio, etc.), que, eventualmente, compaginan con la docencia. Mejor suerte profesional correrán, no obstante, aquellos que habían sido profesores universitarios en España, pues encontrarían en México las condiciones adecuadas para dar continuidad a sus carreras, ingresando en instituciones universitarias y de investigación mexicanas, a las que también accederían con cierta facilidad bastantes profesores de educación secundaria. En su condición de centro de estudios superiores creado, en 1938, para dar cobijo a la elite de la intelectualidad española exiliada en el país, la Casa de España en México, pronto rebautizada como Colegio de México, ofrecerá un incipiente acomodo laboral a un nutrido número de profesores gallegos que, con el transcurso del tiempo, desarrollarían actividades docentes e investigadoras en la Universidad Nacional Autónoma de México —o en otras universidades-, en el Instituto Politécnico Nacional, en la Escuela Normal Superior, etc.

\footnotetext{
${ }^{46}$ Sandra García de Fez, «Una escuela desconocida del exilio: La polémica en torno al Instituto Hispano Mexicano Ruiz de Alarcón», Educació i Història: Revista d'Història de l'Educació 17 (2011): 215.
} 
Hubiesen o no pasado antes por el Colegio de México, desempeñaron labores docentes en centros superiores y universitarios mexicanos de forma estable: Jesús Bal y Gay, Jesús Bernárdez Gómez, Jesús Dopico Ferreiro, Bibiano Fernández Osorio-Tafall, Lorenzo García Méndez, Ramón Iglesia Parga, Xoán López Durá, Alejandro Otero Fernández, Víctor Rico González, Joaquín Seijo Alonso y Carmen Viqueira Landa.

El exilio docente gallego en los EE.UU. tuvo la peculiaridad de ser específicamente universitario, un fenómeno derivado de la muy selectiva política migratoria del país, especialmente celosa en lo concerniente a los antecedentes ideológicos de los republicanos solicitantes de asilo y particularmente interesada en un refugiado perteneciente a la elite intelectual. Con todo, lograrán entrar y establecerse permanentemente como profesores en los EE.UU., gracias, según en qué casos, a la intermediación de las Sociedades Hispanas Confederadas de Nueva York o del hispanista Américo Castro, diez personas, ${ }^{47}$ algunas de las cuales habían desarrollado una relevante actividad política en el período republicano: Emilio González López había sido diputado en Cortes por Izquierda Republicana, Eugenio Fernández Granell había militado en el Partido Obrero de Unificación Marxista, y Ernesto Pérez Guerra, antiguo miembro del Servicio de Información de la República, llevaba algún tiempo en el país en misión oficial, donde lo sorprenderá el final de la guerra. Una vez radicados en los EE.UU., la labor académica, intelectual y publicista, siempre ligada a sus raíces culturales gallegas, que realizaron Emilio González López, Ramón Martínez López y Ernesto Pérez Guerra destacó de manera sobresaliente. Además, en el ámbito artístico fueron muy relevantes las aportaciones de Eugenio Fernández Granell y José Rubia Barcia. ${ }^{48}$

\footnotetext{
${ }^{47}$ En torno al momento de la derrota republicana: Eugenio Fernández Granell (tras un periplo por la República Dominicana, Guatemala y Puerto Rico), Emilio González López (vía directa desde Francia), Ramón Martínez López (tras ejercer en la Universidad de Buenos Aires durante breve tiempo), Ernesto Pérez Guerra y José Rubia Barcia (procedente de Cuba). En 1937 había arribado a los EE. UU. Hernán Poza Juncal, por las circunstancias ya referidas anteriormente. Ramón Iglesia Parga llegará al país, procedente de México, a principios de la década de 1940 para ejercer la docencia universitaria de forma intermitente. En 1946 y 1947, respectivamente, se instalarían, también como profesores universitarios, los hermanos Leonardo (desde Cuba) y Enrique (desde Galicia) Santamarina. Igualmente, en 1947 se establecerá el maestro y pedagogo José Otero Espasandín, pero no como profesor universitario.

${ }^{48}$ Una valiosa contribución reciente sobre esta cuestión es de la autoría del profesor Álex Alonso Nogueira, «Alén da lúa de alén mar: traxectorias dos intelectuais galegos exiliados en Nova York»,
} 
Salvo los casos peculiares de la República Dominicana de Rafael Leónidas Trujillo y de, en alguna medida, Chile, los restantes países americanos a los que arribaron los exiliados gallegos tras la derrota militar republicana distintos a los reseñados con anterioridad fueron generalmente destinos por accidente (falta de plazas en los principales vapores de evacuación, etc.) o a los que llegaron en segunda instancia buscando mejores condiciones de vida después de algún ensayo anterior en otros lugares. Además, se trataba de países con los que no existía una relación migratoria previa más o menos intensa que contribuyese a añadir algún factor de atracción o vínculo. Por tales motivos, el exilio de los docentes gallegos en otros emplazamientos americanos resultó un fenómeno anecdótico. En la República Dominicana se estableció de forma duradera el polémico José Almoina Mateos. En Chile, bien entrada la década de 1940, lo hará Celso Manuel Garrido González, con posterioridad a su aventura argentina. En Panamá, se afincarán Francisca López del Río, vía República Dominicana, en 1940, e Ignacio Herrero Fuentes, en 1941, para ocupar una plaza universitaria tras pasar seis años en Cuba. También de Cuba se marchará el catedrático Sebastián González García-Paz para arraigar, ganándose el pan diario como profesor universitario, en Puerto Rico, adonde dos años después, en 1939, llegará igualmente Francisco Vázquez Díaz. En Venezuela se instalará, en 1939, el profesor de la Universidad de Madrid Leoncio Jaso Roldán y, ya en 1958, el maestro Xosé Velo Mosquera.

En parecidos términos se puede abordar el exilio galaico en los países de Europa, en los que la presencia de docentes gallegos fue episódica, pese a la proximidad geográfica, como consecuencia tanto de la consabida coyuntura geopolítica de preguerra y el talante hostil hacia los refugiados republicanos —incluso de los gobiernos democráticos-, como, una vez más, de la ausencia de una práctica migratoria consolidada y vinculante que pudiese servir de factor coadyuvante. En el vecino Portugal se refugiará, hasta 1947, el maestro Armando Fernández Mazas. En Francia se quedarán los maestros Luis Bazal Rodríguez y Rafael Ochoa Carrasco, y también Manuel Macías Martínez Risco, quien dará continuidad en el país a su carrera de profesor universita-

en Emigración e exilio nos Estados Unidos de América: experiencias de Galicia e Azores, coords. Alberto Pena, Mário Mesquita y Paula Vicente (Santiago de Compostela: Consello da Cultura Galega, 2015), 135-156. 
rio. En Gran Bretaña se establecerá el catedrático Manuel A. Raimúndez Fernández, trabajando como publicista. En Suiza lo hará por breve tiempo el catedrático compostelano con profundas conexiones institucionistas Manuel Varela Radío, y en Italia, toda su vida, como funcionario de la FAO, José María Domínguez García. Y, en su condición de militantes comunistas, los maestros Nieves Álvarez González y Justo Nogueira Gordaliza se irán a la URSS, en donde desarrollarán una dilatada labor docente en varias escuelas.

\section{CODA}

Da título a este ensayo, como a uno de sus capítulos, un verso del poema «Pra A Habana!», perteneciente a Follas novas (1880), de Rosalía de Castro. El poemario había podido ver la luz gracias al subsidio de la Sociedad de Beneficencia de Naturales de Galicia en La Habana, institución de emigrantes de la que la excelsa poeta gallega era socia honoraria desde tan solo un mes después de su fundación formal, en diciembre de 1871. La popularidad y la admiración de las que Rosalía de Castro gozaba en tierras de ultramar, evidenciadas en su rápido madrinazgo de la entidad habanera, habían tenido su origen en la publicación de Cantares gallegos en 1863, un libro en el que ya habían quedado patentes tanto la inquietud de su autora por el problema de la emigración como una tesitura poética inédita, preocupada tanto por acoger y registrar la propia voz y sentir de los emigrantes, como por erigirse en atalaya ilustrada de estampa y denuncia. La misma fórmula se repetirá años después en Follas novas, y son un buen ejemplo de ello los versos "iÁnimo, compañeiros! / Toda a terra é dos homes», en los que la voz poética la ejerce un emigrante que, a punto de iniciar su travesía desde Galicia por el abismo del océano Atlántico, transforma su angustia en una proclama de arrojo que encierra un universo de esperanzas.

Parecida disposición debieron de adoptar los exiliados republicanos gallegos en el momento de la partida, quienes proyectaron sus esperanzas personales y colectivas hacia tierras - familiares, en ocasiones- al otro lado del Atlántico. Allí, en soledad o al arrimo correligionario de otros exiliados - y a veces de las comunidades de emigrantes-, muchos de ellos pondrán todo su talento y capacidad de trabajo al servicio de una tarea que tendría por objeto mantener vivo y dar continuidad al 
proyecto político y cultural republicano y galleguista. Bastantes integrantes del gremio de los docentes serán los primeros en darse cuenta de la responsabilidad que la Historia había puesto encima de sus espaldas e incorporarán a sus vidas este proyecto.

Como se ha dicho anteriormente, el exilio gallego, al igual que el español, fue eminentemente mexicano, si se atiende a criterios con base en argumentos estrictamente cuantitativos, pero, a la hora de determinar protagonismos, es al argentino al que corresponde otorgar - y así se ha hecho hasta el momento en el campo académico- una mayor preeminencia. No en vano, en Buenos Aires tuvo lugar el grueso de la actividad cultural y política galleguista de nuestro exilio. No obstante, justo es reconocer, a los transterrados de otros países, contribuciones sobresalientes. El Consello de Galiza —el Gobierno gallego en el exilio- tendrá su sede en Buenos Aires, pero contará con la cooperación de representantes en otros lugares de América, un servicio que prestarán, precisamente, docentes: Celso Garrido, en Chile; Gerardo Álvarez Gallego, en Cuba; Carlos Velo y Juan L. Durá en México; y Lois Tobío, en Montevideo. Idéntica perspectiva conviene aplicar al ámbito cultural. $\mathrm{Si}$, en rigor, no se puede hablar de un absoluto hiato cultural gallego en las décadas de 1940 y 1950, fue gracias a la intensa actividad de los exiliados en los países americanos, muchos de los cuales habían trabajado en la enseñanza. Este deslumbrante y granítico monumento de creatividad, inteligencia y saber tuvieron que realizarlo, no obstante, como se quejará el pintor Luís Seoane en 1947, sin una finalidad clara y precisa, y al margen de la realidad que debiera servirles de referencia, "pintando y dibujando del recuerdo». Un tremendo drama - «una gran desgracia», en palabras de este insigne representante del exilio gallego-, solo atenuado por la esperanza de que algún día, como la botella lanzada al mar por el náufrago, el mensaje emitido fuese leído al otro lado del océano. Destaponada ya la botella, en esa tarea estamos todavía hoy tantos años después. ${ }^{49}$

\footnotetext{
49 Aunque fue y es una tarea colectiva en la que participaron y participan aún múltiples actores, justo es reconocer que, en el proceso de recuperación del discurso del exilio gallego, ha habido un protagonista pionero y singular, Isaac Díaz Pardo, quien, a través de la editorial Ediciós do Castro y de otras iniciativas, rescató una parte sustantiva de aquel inmenso legado.
} 


\section{Nota sobre el autor}

Gregorio FERreiro FEnTE es profesor de educación secundaria. Licenciado en Filología Gallego-Portuguesa, una parte sustancial de su labor de investigación se ha centrado en el campo del exilio republicano gallego, con especial predilección por el exilio literario. Es autor de libros, artículos y ensayos biográficos, así como de ediciones de obras de escritores gallegos exiliados. Fue profesor en la Universidad de Granada. Actualmente trabaja como asesor técnico docente en el Gobierno gallego, donde realiza proyectos de planificación lingüística. También es profesor colaborador del Centro Autonómico de Formación e Innovación (CAFI) de Galicia.

\section{BIBLIOGRAFÍA}

Alonso Montero, Xesús y Miro Villar. Guerra civil (1936-1939) e literatura galega (textos e documentos para unhas xornadas de estudio e debate). Santiago de Compostela: Consello da Cultura Galega, 1999.

Alonso Montero, Xesús. Intelectuales marxistas e militantes comunistas en Galicia (1926-2006). Vigo: Xerais, 2007.

Alonso Nogueira, Álex. "Alén da lúa de alén mar: traxectorias dos intelectuais galegos exiliados en Nova York». En Emigración e exilio nos Estados Unidos de América: experiencias de Galicia e Azores, coordinado por Alberto Pena, Mário Mesquita y Paula Vicente, 135-156. Santiago de Compostela: Consello da Cultura Galega, 2015.

Alted Vigil, Alicia. La voz de los vencidos. El exilio republicano de 1939. Madrid: Aguilar, 2005.

Álvarez Gila, Óscar. «¿Exilio vasco, exilios vascos? Imágenes y debates entre la historia y la memoria». En Os exilios ibéricos: unha ollada comparada. Nos 70 anos da fundación do Consello de Galiza, editado por Ramón Villares y Xosé M. Núñez Seixas, 293-327. Santiago de Compostela: Consello da Cultura Galega, 2017.

Castelao. Galicia mártir. Madrid-Valencia: Ediciones Españolas, 1937.

Cátedra del Exilio. Proyecto «Exiliados en México. Política y sociabilidad». Centro de Investigaciones Históricas de la Democracia Española de la UNED. https://exiliadosmexico.blogspot.com.

Cid Fernández, Xosé Manuel. «Represión injustificada en la retaguardia franquista. Las víctimas de la Asociación de Trabajadores de la Enseñanza de Ourense». En Entre el olvido y la memoria. Educación, mitos y realidades, editado por Teresa González Pérez, 105-121. Valencia: Tirant Humanidades, 2018. 
Costa Rico, Antón. Historia da educación e da cultura en Galicia. Vigo: Xerais, 2004.

Costa Rico, Antón. "Os ensinantes galegos e o 36. Os mortos e os exiliados». En A II República e a Guerra Civil: actas dos traballos presentados ao II Congreso da Memoria, Culleredo, 1 a 3 de decembro de 2005, compilado por Enrique Barrera et al., 487-521. S.l.: Asociación Cultural Memoria Histórica Democrática, 2006.

Cruz Orozco, José Ignacio. "Maestros y colegios en el exilio republicano de 1939». En Mestres i exili: jornades d'estudi i reflexió, editado por Conrad Vilanaou y Josep Monserrat, 11-31. Barcelona: Universitat de Barcelona, 2002.

Díaz, Hernán M. Historia de la Federación de Sociedades Gallegas: identidades politicas y prácticas militantes. Buenos Aires: Fundación Sotelo Blanco-Biblos, 2007.

Diccionario biobibliográfico de los escritores, editoriales y revistas del exilio republicano de 1939, volúmenes I, II, III y IV, editado por Manuel Aznar Soler y José-Ramón López García. Sevilla: Biblioteca del Exilio-Renacimiento, 2016.

Dieste, Rafael. Obras completas, tomo v: epistolario, editado por Xosé Luís Axeitos. Sada-A Coruña: Ediciós do Castro, 1995.

Domingo Cuadriello, Jorge. El exilio republicano español en Cuba. Madrid: Siglo XXI, 2009.

Duarte, Ángel. «"Dolça Catalunya. Patria del meu cor!”. Glosas al exilio catalanista de primera hora». En Os exilios ibéricos: unha ollada comparada. Nos 70 anos da fundación do Consello de Galiza, editado por Ramón Villares y Xosé M. Núñez Seixas, 329-354. Santiago de Compostela: Consello da Cultura Galega, 2017.

Fernández Santander, Carlos. Alzamiento y guerra civil en Galicia (1936-1939), tomo I. Sada: Ediciós do Castro, 2000.

Ferreiro Fente, Gregorio. «Xosé Otero Espasandín: literatura e exilio». En Xosé Otero Espasandín, Obra galega, editado por María Cuquejo Enríquez, 2841. Santiago de Compostela: Centro Ramón Piñeiro para a Investigación en Humanidades-Xunta de Galicia, 2006.

García de Fez, Sandra. "Una escuela desconocida del exilio: La polémica en torno al Instituto Hispano Mexicano Ruiz de Alarcón». Educació i Història: Revista d'Història de l'Educació 17 (2011): 213-235. https://www.raco.cat/ index.php/EducacioHistoria/article/view/244810/327837.

Gurriarán, Ricardo. Ciencia e conciencia na Universidade de Santiago de Compostela (1900-1940). Do influxo institucionista e a JAE á depuración do professorado. Santiago de Compostela: Servizo de Publicacións e Intercambio Científico da Universidade de Santiago de Compostela, 2006. 
Loita: órgano de Hermandad Gallega [ed. facsimilar]. Santiago de Compostela: Centro Ramón Piñeiro para a Investigación en Humanidades, 1999.

Marquès, Salomó. L'exili dels Mestres (1939-1975). Girona: Universitat de Girona-Llibres del Segle, 1995.

Martínez González, Xurxo. Luís Soto: a xeira pola unidade galega. Vigo: Edicións Xerais de Galicia, 2011.

Martínez Pereda, Lucio. «La depuración franquista del Instituto de Vigo: una primera aproximación». Glaucopis. Boletín del Instituto de Estudios Vigueses 14 (2008/2009): 183-208.

Míguez Macho, Antonio. O que fixemos en Galicia. Ensaio sobre o concepto de práctica xenocida. Ourense: Difusora de Letras, Artes e Ideas, 2009.

Negrín Fajardo, Olegario. «La depuración franquista del profesorado en los institutos de segunda enseñanza de España (1937-1943). Estudio cuantitativo para Galicia». Sarmiento. Anuario Galego de Historia da Educación 10 (2006): 59-99.

Núñez Seixas, Xosé M. «Itinerarios exiliados. Sobre a especificidade do exilio galego de 1936». En O soño da Galiza ideal. Estudos sobre exiliados e emigrantes galegos, 69-125. Vigo: Editorial Galaxia, 2016.

Ortuño Martínez, Bárbara. Hacia el hondo bajo fondo... Inmigrantes y exiliados en Buenos Aires tras la Guerra Civil española. Madrid: Biblioteca Nueva, 2018.

Pena Rodríguez, Alberto. "Galeguismo, franquismo e salazarismo. A colonia e os intelectuais galegos en Portugal durante a Guerra Civil española». En Os exilios ibéricos: unha ollada comparada. Nos 70 anos da fundación do Consello de Galiza, editado por Ramón Villares y Xosé M. Núñez Seixas, 357380. Santiago de Compostela: Consello da Cultura Galega, 2017.

Pereira Martínez, Carlos. «A represión en Culleredo: unha aproximación inicial». En A represión franquista en Galicia: Actas dos traballos presentados ao Congreso da Memoria. Narón, 4 a 7 de decembro de 2003, compilado por Enrique Barrera Beitia et al. 463-499. Narón: Asociación Cultural Memoria Histórica Democrática, 2005.

Proyecto de investigación «Nomes e Voces». Universidade da Coruña, Universidade de Santiago de Compostela y Universidade de Vigo. http://vitimas.nomesevoces.net.

Rubia Barcia, José. Unha vida contada, editado por José Manuel González Herrán. Santiago de Compostela: Consello da Cultura Galega, 2014.

Somoza Cayado, Antonio, Andrés Domínguez Almansa y Lorenzo Fernández Prieto. «La génesis del Régimen franquista en Galicia: aniquilación política y destrucción de la sociedad civil (1936-1939)». En La dictadura franquista: la institucionalització d'un régim, dirigido por Antoni Segura, Andreu Ma- 
yayo y Teresa Abelló, 53-68. Barcelona: Publicacions i Edicions de la Universitat de Barcelona, 2012.

Vázquez González, Alexandre. Emigrantes galegos, trasnsportes e remesas (18301930). S.l.: Consello da Cultura Galega / Fundación Barrié, 2015.

Vázquez Matos, Dania. «La Escuela Libre de La Habana: vivero de inquietudes y desvelos renovadores». En La Literatura y la Cultura del exilio republicano español de 1939: Actas del IV Coloquio Internacional, s/p. Alicante: Biblioteca Virtual Miguel de Cervantes, 2005. http://www.cervantesvirtual.com/ nd/ark:/59851/bmckh0z4.

Velasco Martínez, Luis. «Fascismo de ultramar: la proyección del falangismo en la comunidad española del Río de la Plata (1936-1940)». Memoria para optar al grado de licenciado, Universidad de Santiago de Compostela, 2015.

Vera Jiménez, Fernando. «Cubanos en la Guerra Civil española. La presencia de voluntarios en las Brigadas Internacionales y el Ejército Popular de la República». Revista Complutense de Historia de América 25 (1999): 295-321.

Villares, Ramón. "O Consello de Galiza na estratexia dos exilios ibéricos, 19391950». En Os exilios ibéricos: unha ollada comparada. Nos 70 anos da fundación do Consello de Galiza, editado por Ramón Villares y Xosé M. Núñez Seixas, 15-93. Santiago de Compostela: Consello da Cultura Galega, 2017.

VV.AA. Actas do Congreso Internacional «O exilio galego» (do 24 ao 29 de setembro de 2001) [CD]. Santiago de Compostela: Consello da Cultura Galega, 2006.

VV.AA. Repertorio biobibliográfico do exilio galego: unha achega [CD]. Santiago de Compostela: Consello da Cultura Galega, 2006.

VV.AA. Diccionario biobibliográfico de los escritores, editoriales y revistas del exilio republicano de 1939, volúmenes I, II, III y IV, editado por Manuel Aznar Soler y José-Ramón López García. Sevilla: Biblioteca del Exilio-Renacimiento, 2016.

VV.AA. Os exilios ibéricos: unha ollada comparada. Nos 70 anos da fundación do Consello de Galiza, editado por Ramón Villares y Xosé M. Núñez Seixas. Santiago de Compostela: Consello da Cultura Galega, 2017.

\section{Fuentes}

Arquivo da Emigración do Consello da Cultura Galega. ${ }^{50}$

\footnotetext{
${ }^{50}$ Mi sincero agradecimiento a Carolina García Borrazás y Teresa García Domínguez; también a Emilia García López, responsable de Acción Exterior del Consello da Cultura Galega.
} 